Abstract AB1235 - Table 1. Patient demographics and clinical variables.

\begin{tabular}{|c|c|c|c|c|}
\hline & & $\begin{array}{c}\text { Group A } \\
\text { under current } \\
\text { biological therapy } \\
\text { (for at least } 6 \text { months } \\
n=31\end{array}$ & $\begin{array}{c}\text { Group B } \\
\text { conventional } \\
\text { therapy } \\
\mathrm{n}=29\end{array}$ & $\begin{array}{c}\mathrm{p} \text { - } \\
\text { valu } \\
\mathrm{e}\end{array}$ \\
\hline \multirow[t]{2}{*}{ Patients } & Male, female: n (\%) & $16(52 \%): 15(48 \%)$ & $21(72 \%): 8(28 \%)$ & 0.1 \\
\hline & Age: median (min-max) & $40(29-66)$ & $43(22-66)$ & 0.6 \\
\hline \multirow[t]{3}{*}{ Education } & Primary education (5-11 ages) & 8 & & 0.5 \\
\hline & Secondary education (11-18 ages) & 13 & 15 & \\
\hline & Tertiary education ( $>18$ ages) & 10 & 10 & \\
\hline \multirow[t]{9}{*}{$\begin{array}{l}\text { Clinical } \\
\text { characteristics }\end{array}$} & $\begin{array}{l}\text { Number of anti-TNF; median (min- } \\
\text { max) }\end{array}$ & $1(1-4)$ & $\mathrm{NA}$ & \\
\hline & $\begin{array}{l}\text { Anti-TNF duration (months); mean } \\
\text { (min-max) }\end{array}$ & $30(6-63)$ & $\mathrm{NA}$ & \\
\hline & ASDAS CPR (mean, SD) & $1.59 \pm 0.97$ & $1.95 \pm 1.04$ & 0.1 \\
\hline & BASDAI (mean, SD) & $2.95 \pm 2.13$ & $2.41 \pm 2.11$ & 0.3 \\
\hline & BASFI (mean. SD) & $3.04 \pm 2.92$ & $1.82 \pm 2.43$ & 0.3 \\
\hline & VAS patient $(0-100)$ (mean. SD) & $31.04 \pm 24.53$ & $27.13=28.88$ & 0.4 \\
\hline & VAS physician $(0-100)$ (mean, SD) & $13.35 \pm 15.99$ & $15.98 \pm 16.81$ & 0.5 \\
\hline & ESR $(m m / h)($ mean, SD) & $13.35 \pm 9.05$ & $14.21 \pm 11.11$ & 0.9 \\
\hline & CRP (mo/d) (mean. SD) & $0.56 \pm 0.56$ & $0.74 \pm 0.82$ & 0.4 \\
\hline \multirow{4}{*}{$\begin{array}{l}\text { Work } \\
\text { Productivity } \\
\text { and Activity } \\
\text { Impairment } \\
\text { Questionnaire } \\
\text { in Spa (WPAI) }\end{array}$} & $\begin{array}{l}\text { Absenteeism (Percent work time } \\
\text { missed due to problem) }(\%)\end{array}$ & $7.6 \%$ & $5.8 \%$ & 0.6 \\
\hline & $\begin{array}{l}\text { Presenteeism (Percent impairment } \\
\text { while working due to problem) }(\%)\end{array}$ & $30.9 \%$ & $34 \%$ & 0.7 \\
\hline & $\begin{array}{l}\text { Percent overall work impairment due to } \\
\text { problem }(\%)\end{array}$ & $34.2 \%$ & $35.9 \%$ & 0.9 \\
\hline & $\begin{array}{l}\text { Percent activity impairment due to } \\
\text { problem }(\%)\end{array}$ & $43.5 \%$ & $37.9 \%$ & 0.4 \\
\hline
\end{tabular}

Conclusions: Presenteeism, impairment of work productivity and activity were correlated with disease activity and physical functioning, with the increase of VAS physician resulting in increase in presenteeism. Economic reasons were the major factors to presenteeism and the majority of patients considered that the disease can limit their projects or career progression.

Disclosure of Interest: None declared

DOI: 10.1136/annrheumdis-2018-eular.4280

\section{AB1236 THERAPEUTIC ADHERENCE AND SATISFACTION IN A RHEUMATOLOGY CONSULTATION}

C. Iñiguez Ubiaga, C. Moriano, M. Garijo Bufort, A. Crespo Golmar, I. GonzalezFernandez, C. Alvarez Castro, A. Lopez Robles, M. Martin Martinez, E. Diez Alvarez, T. Perez Sandoval. Unidad de Reumatología, Complejo Hospitalario de León, León, Spain

Background: The lack of treatment adherence to is considered the main reason for therapeutic failure. It entails a high health care cost, both direct and indirect, affecting the patient's morbidity and mortality. In order to measure this adherence, there are different methods, which can be both objective and subjective. The ideal is the combination of both types in order to ensure that the data are as close as possible to reality.

Methods: We carried out an anonymous voluntary survey in October 2017 concerning the degree of satisfaction and therapeutic adherence of patients under follow-up in outpatient Rheumatology Consultations, selecting demographic data from them and using a MARS questionnaire for chronic diseases, which is validated in Spanish. This questionnaire consists of 30 questions that include items about beliefs, experiences and behaviour in terms of health. A score higher than 25 indicates good compliance, while a score lower means a suboptimal compliance.

Results: 201 surveys were collected, excluding those patients whose consultation was the first one and those who rejected their participation. The data analysis was performed descriptively with Microsoft Excel. $61 \%$ of the surveys collected were carried out by women, with an age range between 55 and 70 years (35\%). $45 \%$ of the patients surveyed had a basic level of education and $28 \%$ had an average level of education, representing both of them three quarters of our sample. When we analyse the treatments that our patients receive, the most prevalent are the DMARDs, which represent $35 \%$ of the treatments, followed by the corticotherapy and biological drugs (25\% and $16 \%$ respectively). Approximately $50 \%$ of the survey respondents stated that they had no problems with their medication, and in a small percentage (14\%), they claimed they had problems, mostly digestive in relation to the administration of subcutaneous Methotrexate. A $14.92 \%$ of questionnaires that were not correctly completed were discarded. Out of the 171 surveys, only one respondent was considered to have a good compliance, being the compliance of the remaining respondents suboptimal. This can be influenced by the limitations of understanding due to the language used, taking into account the characteristics of our population, mainly aged and with a primary level of education, as well as the place where the survey was completed. We obtained $74 \%$ of satisfaction with the information shared in the consultation, $73 \%$ considered that enough time was devoted to said consultation and $98 \%$ said they followed the treatment regimens. However, $11 \%$ and $21 \%$ said they changed the regimen according to their lifestyle and according to how the treatment made them feel and only $55 \%$ had clear treatment options available.

Conclusions: The lack of therapeutic adherence is one of the fundamental factors of therapeutic failure. There is no a single method for its assessment. Our patients show a suboptimal therapeutic compliance, although we have to take into account the limitations of the survey carried out. We must bear in mind the sociological aspects that can hinder adherence and re-assess it periodically for possible changes, as well as individualise each patient.

Disclosure of Interest: None declared

DOI: 10.1136/annrheumdis-2018-eular.7399

\section{AB1237 PATIENTS' PERSPECTIVES AND EXPERIENCE OF PSORIASIS AND PSORIATIC ARTHRITIS: A SYSTEMATIC REVIEW AND THEMATIC SYNTHESIS OF QUALITATIVE STUDIES}

D.J. Sumpton ${ }^{1,2,3}$, A. Kelly ${ }^{3,4,5}$, D.J. Tunnicliffe ${ }^{2,3}$, J.C. Craig $^{2,3}$, G. Hassett ${ }^{6}$, D. Chessman ${ }^{6}$, A. Tong ${ }^{2,3}$. 'Department of Rheumatology, Concord Repatriation General Hospital, Sydney; ${ }^{2}$ Sydney School of Public Health, The University of Sydney; ${ }^{3}$ Centre for Kidney Research, The Children's Hospital Westmead, Syndey; ${ }^{4}$ Department of Rheumatology, Canberra Hospital, Canberra; ${ }^{5}$ Department of Rheumatology, Liverpool Hospital, Sydney; ${ }^{6}$ Department of Rheumatology, Liverpool Hospital, Syndey, Australia

Background: Patients with psoriasis and psoriatic arthritis have a lower health related quality of life than the normal population and experience high rates of treatment dissatisfaction ${ }^{1}$. The complexity of unmet needs in diagnosis and treatment ${ }^{2}$ necessitate a deep understanding of the experience of people with both conditions to guide development of outcomes important to patients and improve patient centred care.

Objectives: To describe the perspectives and experiences of patients with psoriasis and psoriatic arthritis.

Methods: Databases (MEDLINE, Embase, PsycINFO, CINAHL) were searched to October 2016. Thematic synthesis was used to analyse the findings.

Results: From 46 studies ( $n=37$ psoriasis and $n=9$ psoriatic arthritis) involving 1290 adult patients with psoriasis $(n=1105)$ and psoriatic arthritis $(n=185)$ we identified six themes (with subthemes): suffering uncontrollable and ongoing upheaval (dictating life choices and course, disrupting role functioning, limited by debilitating symptoms, unstoppable and far reaching fatigue); weighed down by mental load (struggling with unrecognised distress, anxiety provoked by the volatility and constancy of symptoms, depleting motivation and pleasure); harbouring shame and judgement (marked as unhygienic and contagious, rejected and isolated, resenting own appearance, pain and embarrassment in intimacy); demoralised by inadequacies and burden of therapy (disappointed by unmet expectations of treatment benefit, daily drudgery, deterred by unpalatable or inconvenient treatments, disempowered by lack of personalised care, fearing long term side effects); gaining control (making sense of the condition, shutting the disease out, accepting a new health status, attuning to the body); and making confident treatment decisions (trading off perceptible benefits against safety and convenience relying on family input, reassured by clinician acknowledgement of fears, seeking empowering relationships with clinicians).

Conclusions: Patients with psoriasis and psoriatic arthritis contend with profound disruption in their functioning, roles and life course; fear deterioration of their health; and have unmet expectations about their treatment and care. Patients with psoriasis feel marked by their disease, stigmatised and rejected by others while patients with psoriatic arthritis experience social withdrawal and depleted motivation due to fatigue, joint impairment and pain. Establishing therapeutic relationships, addressing treatment expectations, and supporting psychosocial needs may help to improve satisfaction and outcomes in patients with psoriasis and psoriatic arthritis.

\section{REFERENCES:}

[1] Katherine M. Mercy, Kenneth B. Gordon, Amy S. Paller. Patient Satisfaction and Quality of Life in Psoriasis and Psoriatic Arthritis. JAMA. 2014;312 (24):2676-2677

[2] Helliwell, et al. Qualifying Unmet Needs and Improving Standards of Care in Psoriatic Arthritis. Arthritis Care \& Research Vol. 66, No. 12, December 2014, pp 1759-1766

Disclosure of Interest: None declared

DOI: 10.1136/annrheumdis-2018-eular.5161

\section{AB1238 THE SELF-MANAGEMENT MODEL IN THE AGENDA OF SUCCESSIVE CONSULTATIONS IN RHEUMATOLOGY}

D. Castro Corredor. Rheumatology service, Hospital General Universitario De Ciudad Real, Ciudad Real, Spain

Background: The rheumatology service of Ciudad Real Hospital, located in an autonomous community of that same name that is nearly in the centre of Spain, implemented a self-management model of successive appointments more than 